\title{
Review of: "The role of foreign capital and economic freedom in sustainable food production: Evidence from DLD countries"
}

\author{
Donatella Saccone ${ }^{1}$ \\ 1 University of Gastronomic Sciences
}

Potential competing interests: The author(s) declared that no potential competing interests exist.

Through the adoption of various complementary econometric techniques, the paper explores how foreign capital inflows and economic freedom affect food production in developing and least-developed countries. The analysis has the merit to provide empirical evidence about a topic that previous literature has rarely investigated and which, conversely, deserves much attention. In the next decades, indeed, global demographic trends will exert an increasing pressure on food markets, and consequently on food prices, if food production will not properly respond to the expected rise in the demand (FAO, 2017). This is particularly true for those economies that already present significant constraints to food production expansion, i.e. for developing and, especially, least-developed countries. In this context, it seems crucial to understand how national and international policies can contribute to solve or relax such constraints. The paper contributes to this debate by focusing from a national perspective on the role of economic freedom and, from an international point of view, on the role of foreign capital, measured as net inflows of foreign direct investment (FDI) and foreign aid.

While providing interesting evidence, the analysis suffers from some limitations and calls for additional research. First of all, the authors state that the main research question is "what role does foreign capital play in food production in developing and least-developed countries considering the intervening role of economic freedom?". Taking into account the national economic environment is indeed fundamental when the impact of foreign capital is analyzed. In fact, extant literature extensively proved how FDI and foreign aid may have both potential positive and negative effects on recipient countries and that the final outcome much depends on the national policies that are implemented (see Forte and Moura, 2013, for a review). However, what the paper actually does is to measure the direct effect that economic freedom and foreign capital singularly have on food production without verifying how they interact in determining the final outcome. The use of either interaction terms or more sophisticated techniques may contribute to answer such a question and give more meaningful insights.

Second, the findings presented in the paper need to be supported by some additional robustness tests. On the one hand, it would be informative to check if and how they change when alternative sub-samples are 
used, like food importing and food exporting countries, low and middle income countries, countries with different levels of economic freedom, etc. On the other hand, more control variables should be added, especially representing geographic and climate factors. This would allow to exclude that the statistical relation found between foreign capital and food production is the outcome of a correlation that both variables have with other factors, like the endowment of arable land (in the case of FDI it is reasonable to assume that, other things being equal, they go where geographic and agricultural conditions are more favorable) or climate conditions (foreign aid is often intensified when a country is facing the aftermath of natural disasters and catastrophic events, which also have an effect on food production).

Third and most important, the analysis only focuses on the quantity of food production but nothing tells about how the quality and composition of food production change when foreign capital inflows grow. While it is not explicitly the aim of the study, I think it is the real core of the problem when sustainable food production is mentioned (as the paper does). Potentially, an increase in food production could not be fully sustainable if it has negative environmental and social impacts which, in the long-run, may negatively affect back food production and, more generally, people's food security. In recipient countries agricultural FDI, for example, have been sometimes associated to environmental degradation (Sabir et al., 2020), loss of sovereignty on land (Cotula et al., 2009), and changing consumption patterns towards more processed and unhealthy food (Miljkovic et al., 2015). As a consequence, a more integrated approach, as stressed by the UN Agenda 2030 (UN, 2015), is fundamental to evaluate the multidimentional and long-term sustainability of food production. In fact, SDG 2 emphasizes the role that local and small-scale food producers play on sustainable food production, where 'sustainable' does not only refer to the quantity of produced food but also and above all to its economic, social and environmental implications. What role does foreign capital play on it? To answer this question, a more detailed analysis is necessary. To this purpose, distinguishing the short- from the long-term impacts of foreign capital seems fundamental, as they could diverge. The paper tries to do it by using GMM estimation techniques which, however, are able to capture long-terms dynamics only partially and do not record potential discontinuity in the sign of the effect at different periods in time. Moreover, future research should go beyond the exclusively quantitative perspective and also investigate the impact that foreign capital has on the economic, social and environmental sustainability of food production, as this represents the central matter in the debate aforementioned.

Finally, as the authors recognize in the last section of the paper, it would be interesting to break down economic freedom into its different dimensions (to this purpose the Fraser Institute Index of Economic Freedom provides a good coverage over time and space) as well as foreign capital into various sectors, especially focusing on FDI in agriculture and on food aid. This would give rise to more specific and consistent policy considerations. 


\section{References}

Cotula L., Vermeulen S., Leonard R., Keeley J. (2009), Land grab or development opportunity? Agricultural investment and international land deals in Africa. IIED/FAO/IFAD, London/Rome.

FAO (2017), The future of food and agriculture - Trends and challenges. Rome.

Forte R., Moura R. (2013), The effects of foreign direct investment on the host country's economic growth: theory and empirical evidence. The Singapore Economic Review, 58(03), 1350017.

Miljkovic D., Shaik S., Miranda S., Barabanov N., Liogier A. (2015), Globalisation and Obesity. World Econ, 38, 1278-1294.

Sabir S., Qayyum U., Majeed T. (2020), FDI and environmental degradation: the role of political institutions in South Asian countries. Environ Sci Pollut Res, 27, 32544-32553.

UN (2015), Transforming our world: the 2030 Agenda for Sustainable Development, Resolution adopted by the General Assembly (A/RES/70/1), 25 September. 